\title{
Cloud Point Extraction as an Advantageous Preconcentration Approach for Analysis of Trace Silver Nanoparticles in Environmental Waters
}

\author{
Jing-fu Liu,*,† Jing-bo Chao,, ${ }^{+\neq}$Rui Liu, ${ }^{\dagger}$ Zhi-qiang Tan, ${ }^{\dagger}$ Yong-guang Yin, ${ }^{\dagger}$ Yuan Wu, ${ }^{\dagger}$ and \\ Gui-bin Jiang ${ }^{\dagger}$
}

\begin{abstract}
State Key Laboratory of Environmental Chemistry and Ecotoxicology, Research Center for Eco-Environmental Sciences, Chinese Academy of Sciences, P.O. Box 2871, Beijing 100085, China, Chemical Metrology and Analytical Science Division, National Institute of Metrology, Beijing 100013, P. R. China
\end{abstract}

Silver nanoparticles (AgNPs) were selectively concentrated from environmental water samples without disturbing their sizes and shapes by cloud point extraction (CPE) with Triton X-114 (TX-114). The highest extraction efficiency for AgNPs was obtained at about their zero point charge $\mathrm{pH}$ ( $\mathrm{pH}_{\mathrm{PZC}}$ ), which was $\sim 3.0-3.5$ for the studied AgNPs. Addition of salts such as $35 \mathrm{mM} \mathrm{NaNO}$ or $10 \mathrm{mM} \mathrm{Na} \mathrm{S}_{2} \mathrm{O}_{3}$ enhanced the phase separation and thus increased the extraction efficiency of AgNPs. Furthermore, $\mathrm{Na}_{2} \mathrm{~S}_{2} \mathrm{O}_{3}$ efficiently eliminated the interference of $\mathrm{Ag}^{+}$due to the formation of a complex between $\mathrm{Ag}^{+}$and $\mathrm{S}_{2} \mathrm{O}_{3}{ }^{2-}$ that was not extracted into the TX-114-rich phase. The presence of humic acid at an environmentally relevant level $(0-30 \mathrm{mg} / \mathrm{L}$ dissolved organic carbon) had no effect on the extraction of AgNPs. An enrichment factor of 100 was obtained with $0.2 \%(\mathrm{w} / \mathrm{v}) \mathrm{TX}-114$, and the recoveries of AgNPs from various environmental samples were in the range of $57-116 \%$ at $0.1-146 \mu \mathrm{g} / \mathrm{L}$ spiked levels. The AgNPs preconcentrated into the TX-114-rich phase were identified by transmission electron microscopy/scanning electron microscopy-energy dispersive spectrometer/UV-vis spectrum and quantified after microwave digestion by inductively coupled plasma mass spectrometry with a detection limit of $0.006 \mu \mathrm{g} / \mathrm{L}(34.3$ fmol/L particles of AgNPs). As the proposed CPE procedure preserves the sizes and shapes of AgNPs, the original morphology of AgNPs in environmental waters can be obtained by characterizing the preconcentrated analytes in the TX-114-rich phase. This proposed method provides an efficient approach for the analysis and tracking of AgNPs in the environment.

Given their large quantity of production and widespread applications, engineered nanomaterials (NMs) will inevitably be released into the environment during production, handling, and disposal. The unique properties of NMs, such as high surfaceto-volume ratio, mobility and catalytic activity, could cause adverse effects on the eco-environmental system. Evaluation of the risk

* Corresponding author. E-mail: jfliu@rcees.ac.cn. Fax: +86-10-62849192.

$\dagger$ Chinese Academy of Sciences.

* National Institute of Metrology. of NMs to human health and the environment relies on the understanding of their fate, transport, and exposure, as well as their effects on the fate, transport, and exposure of other toxic substances. However, little is known about the occurrence, fate, and toxicity of NMs, partly due to the lack of quantitative methodology for NMs in environmental and biological matrixes. ${ }^{1-6}$

A variety of methods have been developed for characterization and quantitative analysis of NMs in simple matrixes, as well as natural NMs in a complex matrix such as environmental waters and soils. ${ }^{7-12}$ Characterization was mainly conducted with microscopy and microscopy-related techniques (e.g., scanning electron microscopy (SEM), transmission electron microscopy (TEM), and atomic force microscopy (AFM)), whereas quantification was mainly based on the coupling of size separation techniques (e.g., size-exclusion chromatography, ${ }^{13-15}$ field flow fractionation, ${ }^{16-18}$ hydrodynamic chromatography, ${ }^{19,20}$ and capillary electrophoresis ${ }^{21-24}$ ) with various detectors (e.g., UV, ${ }^{13-15}$ mass spectromety (MS), and inductively coupled plasma mass spectrometry (ICPMS) ${ }^{17}$ ). However, reports on the determination of engineered $\mathrm{NMs}$ in environmental/biological samples and consumer products are sparse. Fullerenes $\left(\mathrm{C}_{60}\right)$ were determined by high-performance liquid chromatography (HPLC) coupled

(1) Colvin, V. L. Nat. Biotechnol. 2003, 21, 1166-1170.

(2) USEPA. U.S. Environmental Protection Agency Nanotechnology White Paper, 2007.

(3) Maynard, A. D.; Aitken, R. J.; Butz, T.; Colvin, V.; Donaldson, K.; Oberdorster, G.; Philbert, M. A.; Ryan, J.; Seaton, A.; Stone, V.; Tinkle, S. S.; Tran, L.; Walker, N. J.; Warheit, D. B. Nature 2006, 444, 267-269.

(4) Wiesner, M. R.; Lowry, G. V.; Alvarez, P.; Dionysiou, D.; Biswas, P. Environ. Sci. Technol. 2006, 40, 4336-4345.

(5) Klaine, S. J.; Alvarez, P. J. J.; Batley, G. E.; Fernandes, T. F.; Handy, R. D.; Lyon, D. Y.; Mahendra, S.; McLaughlin, M. J.; Lead, J. L. Environ. Toxicol. Chem. 2008, 27, 1825-1851.

(6) Farre, M.; Gajda-Schrantz, K.; Kantiani, L.; Barcelo, D. Anal. Bioanal. Chem. 2009, 393, 81-95.

(7) Wigginton, N. S.; Haus, K. L.; Hochella, M. F. J. Environ. Monit. 2007, 9, 1306-1316.

(8) Hassellov, M.; Readman, J. W.; Ranville, J. F.; Tiede, K. Ecotoxicology 2008, 17, 344-361.

(9) Tiede, K.; Boxall, A. B. A.; Tear, S. P.; Lewis, J.; David, H.; Hassellov, M. Food Addit. Contam. 2008, 25, 795-821.

(10) Tiede, K.; Hassellov, M.; Breitbarth, E.; Chaudhry, Q.; Boxall, A. B. A. J. Chromatogr., A 2009, 1216, 503-509.

(11) Simonet, B. M.; Valcarcel, M. Anal. Bioanal. Chem. 2009, 393, 17-21.

(12) Utsunomiya, S.; Ewing, R. C. Environ. Sci. Technol. 2003, 37, 786-791.

(13) Al-Somali, A. M.; Krueger, K. M.; Falkner, J. C.; Colvin, V. L. Anal. Chem. 2004, 76, 5903-5910. 
with UV ${ }^{25-27}$ or MS detectors, ${ }^{28,29}$ while metal and metal oxide NMs were analyzed on the basis of the quantification of the metal ions by destructive elemental analysis instruments such as ICPMS $^{30,31}$ and inductively coupled plasma optical emission spectrometer (ICP-OES) ${ }^{32}$ after sample digestion. Recently AgNPs in sanitizer gel and fabric were determined by a rhodamine-based fluorogenic and chromogenic probe after oxidation of AgNPs to $\mathrm{Ag}^{+}$with hydrogen peroxide. ${ }^{33}$

Because of the extremely low concentration of engineered $\mathrm{NMs}$ and the complex matrixes in real environmental and biological samples, a separation step that not only can preconcentrate NMs but also preserve the size and shape of NMs is urgently needed to couple with various detection and characterization instruments for tracking NMs in the environment. Up to now, methods for extraction of NMs in environmental and biological samples are sparsely reported. Fullerenes $\left(\mathrm{C}_{60}\right)$ were extracted from environmental waters ${ }^{28,29}$ and biological samples ${ }^{25-27}$ with toluene $^{25-28}$ and from environmental waters by solid-phase extraction. ${ }^{29}$ Nanocopper pollutants in wastewater were extracted with ionic liquids in the direction of wastewater treatment. ${ }^{34}$

Extraction of trace NMs from complex matrixes is a great challenge and is now the bottleneck that hinders the quantitative determination and characterization of NMs in environmental and biological samples. To overcome this bottleneck, development of general, simple, and cost-effective approaches for extracting NMs is essential. Very recently, our study ${ }^{35}$ demonstrated that cloud point extraction (CPE) with a commercially available and lowcost surfactant (Triton X-114, TX-114) is generally applicable for reversible concentration/separation of NMs from aqueous disper-

(14) Huang, X.; Mclean, R. S.; Zheng, M. Anal. Chem. 2005, 77, 6225-6228.

(15) Krueger, K. M.; Al-Somali, A. M.; Falkner, J. C.; Colvin, V. L. Anal. Chem. 2005, 77, 3511-3515.

(16) Gidding, J. C. Science 1993, 260, 1456-1465.

(17) Hassellov, M.; Lyven, B.; Haraldsson, C.; Sirinawin, W. Anal. Chem. 1999, 71, 3497-3502.

(18) Lee, W. J.; Min, B.-R. Anal. Chem. 1999, 71, 3446-3452.

(19) Chela, E.; Tijssen, R.; Blom, M. T.; Gardeniers, H. J. G. E.; van den Berg, A. Anal. Chem. 2002, 74, 3470-3475.

(20) Tiede, K.; Boxall, A. B. A.; Tiede, D.; Tear, S. P.; David, H.; LewisJ. J. Anal. At. Spectrom. 2009, DOI: 10.1039/b822409a.

(21) Doorn, S. K.; Fields, R. E.; Hu, H.; Hamon, M. A.; Haddon, R. C.; Selegue, J. P.; Majidi, V. J. Am. Chem. Soc. 2002, 124, 3169-3174.

(22) Lo, C. K.; Paau, M. C.; Xiao, D.; Choi, M. F. Anal. Chem. 2008, 80, 24392446.

(23) Vicente, G.; Colon, L. A. Anal. Chem. 2008, 80, 1988-1994.

(24) López-Pastor, M.; Domínguez-Vidal, A.; Ayora-Cañada, M. J.; Simonet, B. M.; Lendl, B.; Valcárcel, M. Anal. Chem. 2008, 80, 2672-2679.

(25) Santa, T.; Yoshioka, D.; Homma, H.; Imai, K.; Satoh, M. I. T. Biol. Pharm. Bull. 1995, 18, 1171-1174.

(26) Moussa, F.; Pressac, M.; Genin, E.; Roux, S.; Trivin, F.; Rassat, A.; Ceolin, R.; Szwarc, H. J. Chromatogr., B 1997, 696, 153-159.

(27) Xia, X. R.; Monteiro-Riviere, N. A. J. E. R. J. Chromatogr., A 2006, 1129, 216-222.

(28) Isaacson, C. W.; Usenko, C. Y.; Tanguay, R. L.; Field, J. A. Anal. Chem. 2007, 79, 9091-9097.

(29) Chen, Z.; Westerhoff, P.; Herckes, P. Environ. Toxicol. Chem. 2008, 27, 1852-1859.

(30) Zhang, X.; Sun, H.; Zhang, Z.; Niu, Q.; Chen, Y.; Crittenden, J. C. Chemosphere 2007, 67, 160-166.

(31) Navarro, E.; Piccapietra, F.; Wagner, B.; Marconi, F.; Kaegi, R.; Odzak, N.; Sigg, L.; Behra, R. Environ. Sci. Technol. 2008, 42, 8959-8964.

(32) Benn, T. M.; Westerhoff, P. Environ. Sci. Technol. 2008, 42, 4133-4139.

(33) Chatterjee, A.; Santra, M; Won, N.; Kim, S.; Kim, J. K.; Kim, S. B.; Ahn, K. H. J. Am. Chem. Soc. 2009, 131, 2040-2041.

(34) Huang, H.-L.; Wang, H. P.; Wei, G.-Z.; Sun, I.-W.; Huang, J.-F.; Yang, Y. W. Environ. Sci. Technol. 2006, 40, 4761-4764.

(35) Liu, J.-F.; Liu, R.; Yin, Y.-G.; Jiang, G.-B. Chem. Commun. 2009, 15141516. sions. Furthermore, the size and shape of NMs were preserved during phase transfer and storage in a surfactant-rich phase. Thus, it is expected that TX-114-based CPE has the potential to be applied in extracting engineered NMs from environmental waters. To the best of our knowledge, there is currently no report on exploring the applicability of CPE in the analysis of NMs though $\mathrm{CPE}$ has been widely used as a sample pretreatment technique in environmental and biological analyses. ${ }^{36-38}$

Silver nanoparticles (AgNPs) are already widely used as bactericides in numerous consumer products such as textiles and personal care products. ${ }^{3}$ It is likely that AgNPs will be released into the environment and thus might exert adverse effects on the environment. Only limited studies on the fate and behavior of AgNPs have been reported. ${ }^{31,32}$ In these studies, quantification of AgNPs was based on the difference between the total $\mathrm{Ag}$ concentration and the free $\mathrm{Ag}^{+}$concentration. The total $\mathrm{Ag}$ concentration was obtained by ICPMS ${ }^{31}$ or ICP-OES ${ }^{32}$ after sample digestion, whereas the free $\mathrm{Ag}^{+}$concentration was detected before digestion with a silver selective electrode ${ }^{31,32}$ after separation by centrifugation ${ }^{32}$ or centrifugal ultrafiltration. ${ }^{31}$ The labile $\mathrm{Ag}^{+}$was also determined by ICPMS after sampling with diffusive gradients in thin films (DGT). ${ }^{31}$ If AgNPs can be extracted and concentrated from water samples without disturbing their size and shape, AgNPs in environmental samples could be characterized and quantified with high sensitivity, providing further understanding of the fate and toxicity of AgNPs in aqueous systems. ${ }^{32}$

In this present study, a preconcentration method based on the CPE technique with TX-114 was developed for quantification and characterization of trace AgNPs in environmental waters. After CPE with TX-114, the trace AgNPs concentrated in the TX-114rich phase was separated for characterization with TEM/SEMenergy dispersive spectrometer (EDS)/UV-vis spectrum and for quantification by ICPMS after microwave digestion.

\section{EXPERIMENTAL SECTION}

Chemicals and Materials. TX-114 and polyvinylpyrrolidone (PVP) were purchased from Acros Organics (Geel, Belgium). Humic acid (Sigma-Aldrich, Saint Louis, MO) with 35.1\% dissolved organic carbon (DOC) was used as obtained. Nitric acid (65\%) was obtained from Merck (Darmstadt, Germany). $\mathrm{Ag}^{+}$stock solution $(100 \mathrm{mg} / \mathrm{L})$ was prepared by dissolution of $\mathrm{AgNO}_{3}$ in $0.4 \mathrm{M} \mathrm{HNO}_{3}$. All other chemicals were analytical-reagent grade or above and were obtained from Sinopharm Chemical Reagent Beijing (Beijing, China). Ultrapurified water (EASY-pure LF, Barnstead International, Dubuque, IA) was used throughout the experiments.

Preparation of AgNPs. The PVP capped AgNPs were synthesized by reduction of $\mathrm{AgNO}_{3}$ with sodium hypophosphite and stabilized with PVP. ${ }^{39}$ Details are shown in the Supporting Information. Stock suspensions of PVP capped AgNPs were prepared by redispersion of the PVP capped AgNPs with water. Commercial AgNPs were obtained by extraction of pieces of

(36) Quina, F. H.; Hinze, W. L. Ind. Eng. Chem. Res. 1999, 38, 4150-4168.

(37) Rubio, S.; Perez-Bendito, D. Trends Anal. Chem. 2003, 22, 470-485.

(38) Paleologos, E. K.; Giokas, D. L.; Karayannis, M. I. Trends Anal. Chem. 2005, $24,426-436$.

(39) Mayer, A. B. R.; Grebner, W.; Wannemacher, R. J. Phys. Chem. B 2000, 104, 7278-7285. 
wound dressings (ACTICOAT Flex, Smith and Nephew, Canada), which was acknowledged to contain AgNPs (Silcryst nanocrystalline silver), with water for $24 \mathrm{~h}$. After centrifugation at 17000 rpm ( 19 $000 \mathrm{~g}$ ) for $20 \mathrm{~min}$, the AgNPs were concentrated until the lower phase became a yellow color and the upper phase became transparent and colorless. The AgNPs in the lower phase were collected and redispersed with water for use as stock dispersions of commercial AgNPs. The AgNPs stock dispersions were kept in the dark and used for one week, whereas the working dispersions were prepared and quantified by ICPMS daily.

Measurement of Free $\mathbf{A g}^{+}$in AgNP Dispersions. The free $\mathrm{Ag}^{+}$concentrations in $\mathrm{AgNP}$ suspensions were determined with a $\mathrm{pH} / \mathrm{mV}$ meter (Orion 4 Star $\mathrm{pH} / \mathrm{ISE}$ Benchtop, Thermo Scientific, Waltham, MA) equipped with a silver/sulfide ionselective electrode (Van-Landon pHoenix, Houston, TX). Measurement was conducted based on the user guide of the silver ion-selective electrode, but $0.02 \mathrm{M}$ rather than $0.1 \mathrm{M} \mathrm{NaNO}_{3}$ was adopted to avoid the formation of precipitation at a high concentration of $\mathrm{Ag}^{+}$.

Characterization of AgNPs. The absorbance spectra of the two types of AgNPs were recorded with a multimode microplate spectrophotometer (Varioscan Flash, Thermo). The $\zeta$ potential of AgNPs was measured at varied $\mathrm{pH}$ in the range of $\mathrm{pH} 3-13$ and $\mathrm{pH} 3-9$ for the PVP capped and commercial AgNPs, respectively, with a Malvern Nano ZS (Malvern Instruments, UK).

TEM was carried out with an H-7500 (Hitachi, Japan) at 80 $\mathrm{kV}$, while SEM was performed with S-4800 (Hitachi, Japan) coupled with an EDS (Oxford, UK) at $15 \mathrm{kV}$. TEM samples were prepared by loading $5 \mu \mathrm{L}$ aliquots of the aqueous sample or the TX-114-rich phase (at 30× dilution with 1:1 water and methanol) onto carbon-coated grid sample holders. The size distribution of the nanoparticles was estimated using Image-Pro plus software and Gaussian fitting. At least 300 particles were counted from multipicture in each case. SEM samples were prepared by loading $10 \mu \mathrm{L}$ aliquots of the aqueous sample or the TX-114-rich phase onto a carbon supporter.

CPE of AgNPs. A $9.5 \mathrm{~mL}$ AgNP sample solution placed in a $10 \mathrm{~mL}$ long tapered glass centrifuge tube was adjusted to $\mathrm{pH} 3.0$ with diluted $\mathrm{HNO}_{3}$, and then $0.1 \mathrm{~mL}$ of $1 \mathrm{M} \mathrm{Na}_{2} \mathrm{~S}_{2} \mathrm{O}_{3}$ or $0.1 \mathrm{~mL}$ of $3.5 \mathrm{M} \mathrm{NaNO}_{3}$ and $0.4 \mathrm{~mL}$ of $5 \%$ (w/v) TX-114 were added in sequence. The mixture was mixed and incubated at $40{ }^{\circ} \mathrm{C}$ in a water bath for $30 \mathrm{~min}$, and the tube was centrifuged at 2000 $\mathrm{rpm}(\sim 640 \mathrm{~g})$ at room temperature for $5 \mathrm{~min}$ to facilitate the phase separation. The obtained TX-114-rich phase $(\sim 100 \mu \mathrm{L})$ with the concentrated AgNPs was collected for quantification or characterization. PVP capped AgNPs were used in the optimization of the extraction parameters unless otherwise specified.

Microwave Digestion and ICPMS Determination of AgNPs. For determination of the total Ag content, the obtained TX114-rich phase was digested using a CEM Mars 5 Xpress (Matthews, NC) with a microwave-assisted digestion procedure modified from the U.S. EPA method 3052 (see details in the Supporting Information). AgNPs were quantified by measuring the $\mathrm{Ag}$ content in the digested sample solution by ICPMS (Agilent 7500ce) with $\mathrm{Ag}$ standard solutions prepared by diluting a certified reference material $(1000 \mathrm{mg} / \mathrm{L} \mathrm{Ag}$, GBW08610, National Institute of Metrology, China) with 5\% (v/v) $\mathrm{HNO}_{3}$. Experiments showed that the recovery of $\mathrm{Ag}$ was over $95 \%$.

Water Sample Collection. Municipal sewage influent ( $\mathrm{pH} 7.8$, $11.3 \mathrm{mg} / \mathrm{L} \mathrm{DOC}$ ) and effluent (pH 7.3, $13.2 \mathrm{mg} / \mathrm{L}$ DOC) were collected at Gaobeidian wastewater treatment plant (WWTP) in the east part of Beijing (China). River water (pH 7.6, $4.5 \mathrm{mg} / \mathrm{L}$ DOC) was collected upstream of Taihu lake (Zhejiang, China). Lake water ( $\mathrm{pH} 7.6,11.9 \mathrm{mg} / \mathrm{L}$ DOC) was collected from a lake in the suburb of Shijiazhuang (Hebei, China).

\section{RESULTS AND DISCUSSION}

Purity and Stability of AgNP Suspensions. The free $\mathrm{Ag}^{+}$ (measured by an ion-selective electrode) relative to the total $\mathrm{Ag}$ (measured by ICPMS) was 1.9\% and 3.0\% for the stock suspensions of PVP capped AgNPs and the commercial AgNPs, respectively. For both the PVP capped AgNPs and the commercial AgNP stock dispersions, the free $\mathrm{Ag}^{+}$contents remained constant during a period of 7 days. With prolonged storage to 6 months, however, the proportion of free $\mathrm{Ag}^{+}$in the PVP capped AgNP stock suspensions increased to 9.4\%. In order to avoid the dissolution of AgNPs, the stock suspensions of the AgNPs were prepared every week, whereas the AgNP working suspensions were freshly prepared and quantified by ICPMS on a daily basis.

Optimization of the CPE Parameters. Parameters that commonly affect the CPE efficiency, such as salt content, surfactant concentration, temperature, $\mathrm{pH}$, and incubation time, were optimized with individual solutions or a mixture of $\mathrm{Ag}^{+}(1.0 \mathrm{mg} /$ L) and AgNPs (0.93 mg/L).

Unlike in the $\mathrm{CPE}$ of traditional organic compounds and metal ions where ionic strength has no apparent effect on the extraction efficiency, ${ }^{36-38}$ our previous study ${ }^{35}$ demonstrated that the ionic strength plays an important role in the CPE of NMs. The presence of salt in dispersions markedly enhanced the extraction efficiency of various $\mathrm{NMs}$ at a $\mathrm{pH}$ far from their zero point charge $\mathrm{pH}$ $\left(\mathrm{pH}_{\mathrm{PZC}}\right)$, as the presence of $\mathrm{NaCl}$ reduced the Coulomb repulsion between the charged NMs in TX-114 micelles and thus enhanced the phase separation. In this study, $\mathrm{Na}_{2} \mathrm{~S}_{2} \mathrm{O}_{3}$ was added to function as a salt to enhance the extraction of $\mathrm{AgNPs}$ and, as a complex reagent of $\mathrm{Ag}^{+}$, to prevent the extraction of $\mathrm{Ag}^{+}$into the TX-114-rich phase.

Figure 1 shows the impact of $\mathrm{Na}_{2} \mathrm{~S}_{2} \mathrm{O}_{3}$ concentration on the apparent extraction efficiency of AgNPs with the presence and absence of $\mathrm{Ag}^{+}$, respectively. In both cases, the extraction efficiency increased with a $\mathrm{Na}_{2} \mathrm{~S}_{2} \mathrm{O}_{3}$ concentration up to $10 \mathrm{mM}$, due to the salt effect of $\mathrm{Na}_{2} \mathrm{~S}_{2} \mathrm{O}_{3}$, and then remained constant up to $30 \mathrm{mM}$. At $\mathrm{Na}_{2} \mathrm{~S}_{2} \mathrm{O}_{3}$ concentrations below $10 \mathrm{mM}$, the apparent extraction efficiency of AgNPs in the mixture of $\mathrm{AgNPs}$ and $\mathrm{Ag}^{+}$was slightly higher than that in the $\mathrm{AgNPs}$. We speculate that, in the mixture of $\mathrm{Ag}^{+}$and $\mathrm{AgNPs}$, parts of the coexisted $\mathrm{Ag}^{+}$were adsorbed on the surface of AgNPs and were coextracted with AgNPs into the surfactant-rich phase, causing higher apparent extraction efficiency than that in a $\mathrm{AgNP}$ solution. With the increase of $\mathrm{S}_{2} \mathrm{O}_{3}{ }^{2-}$ concentration, some of the $\mathrm{Ag}^{+}$adsorbed on the AgNP surface was desorbed by forming a complex with $\mathrm{S}_{2} \mathrm{O}_{3}{ }^{2-}$ and remained in the aqueous phase, reducing the apparent extraction efficiency. To verify this, we compared the respective extraction efficiency of $\mathrm{Ag}^{+}$, 


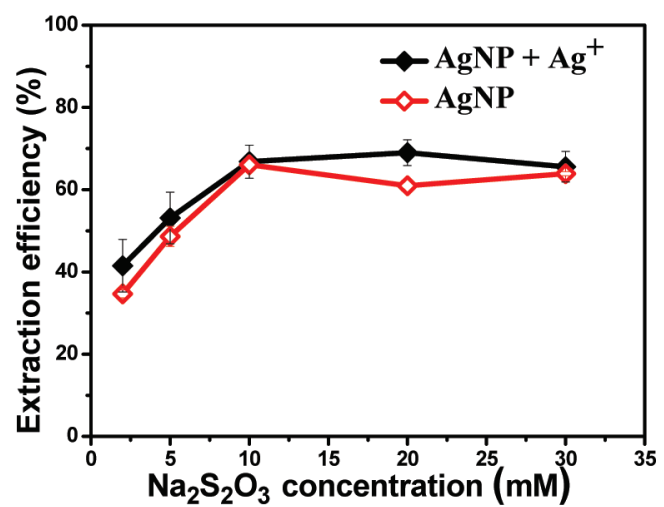

Figure 1. Effect of $\mathrm{Na}_{2} \mathrm{~S}_{2} \mathrm{O}_{3}$ concentration on the extraction efficiency of AgNPs. To $10 \mathrm{~mL}$ of $0.93 \mathrm{mg} / \mathrm{L} \mathrm{AgNPs}$ or a mixture of $10 \mathrm{mg} / \mathrm{L}$ $\mathrm{Ag}^{+}$and $0.93 \mathrm{mg} / \mathrm{L} \mathrm{AgNPs}$ was added $0.2 \%(\mathrm{~m} / \mathrm{v}) \mathrm{TX}-114$ and various contents of $\mathrm{Na}_{2} \mathrm{~S}_{2} \mathrm{O}_{3}$. The resulting solution was incubated at $40{ }^{\circ} \mathrm{C}$ for $30 \mathrm{~min}$.

Table 1. Extraction Efficiencies of $\mathrm{Ag}^{+}(1.0 \mathrm{mg} / \mathrm{L})$, AgNPs $(0.93 \mathrm{mg} / \mathrm{L})$, or a Mixture of $\mathrm{Ag}^{+}(1.0 \mathrm{mg} / \mathrm{L})$ and AgNPs $(0.93 \mathrm{mg} / \mathrm{L})$ in Various Matrixes by the Proposed Cloud Point Extraction Procedure

\begin{tabular}{crcc} 
& \multicolumn{3}{c}{ extraction efficiency (\%, mean $\pm \mathrm{s}, n=3$ ) } \\
\cline { 2 - 4 } sample matrix & \multicolumn{1}{c}{$\mathrm{Ag}^{+}$} & $\mathrm{AgNPs}$ & $\mathrm{Ag}^{+}+\mathrm{AgNPs}$ \\
$10 \mathrm{mM} \mathrm{Na}_{2} \mathrm{~S}_{2} \mathrm{O}_{3}$ (pH 5.9) & $1.6 \pm 0.2$ & $65.1 \pm 2.7$ & $69.8 \pm 2.7^{a}$ \\
$35 \mathrm{mM} \mathrm{NaNO}_{3}$ (pH 5.6) & $3.5 \pm 0.4$ & $64.4 \pm 2.6$ & $72.4 \pm 3.3^{a}$ \\
$10 \mathrm{mM} \mathrm{HNO}_{3}$ (pH 2.1) & $1.4 \pm 0.1$ & $41.0 \pm 8.6$ & $72.2 \pm 3.1^{a}$ \\
$100 \mathrm{mM} \mathrm{HNO}_{3}$ (pH 1.1) & $14.8 \pm 1.1$ & $84.8 \pm 1.4$ & $90.0 \pm 4.2^{b}$
\end{tabular}

${ }^{a}$ Apparent extraction efficiency calculated with respect to $0.93 \mathrm{mg} / \mathrm{L}$ AgNPs and assuming $\mathrm{Ag}^{+}$was not extracted. ${ }^{b}$ Apparent extraction efficiency calculated with respect to $0.93 \mathrm{mg} / \mathrm{L}$ AgNPs and assuming $15 \%$ of $\mathrm{Ag}^{+}$was extracted.

AgNPs, and a mixture of $\mathrm{Ag}^{+}$and $\mathrm{AgNPs}$ in $10 \mathrm{mM} \mathrm{Na}_{2} \mathrm{~S}_{2} \mathrm{O}_{3}$, $35 \mathrm{mM} \mathrm{NaNO}_{3}, 10 \mathrm{mM} \mathrm{HNO}_{3}$, and $100 \mathrm{mM} \mathrm{HNO}_{3}$. As shown in Table $1, \mathrm{Na}_{2} \mathrm{~S}_{2} \mathrm{O}_{3}$ was preferred as it significantly reduced the extraction of $\mathrm{Ag}^{+}$and eliminated the interference of $\mathrm{Ag}^{+}$ in the mixture of $\mathrm{Ag}^{+}$and $\mathrm{AgNPs}$. However, as $\mathrm{S}_{2} \mathrm{O}_{3}{ }^{2-}$ interfered with the UV-vis identification of AgNPs (see details in Identification of AgNPs), we recommend use of $35 \mathrm{mM} \mathrm{NaNO}_{3}$ as a phase separation facilitator for UV-vis identification of AgNPs, whereas using $10 \mathrm{mM} \mathrm{Na}_{2} \mathrm{~S}_{2} \mathrm{O}_{3}$ as a phase separation facilitator for other analyses of AgNPs. We further tested the AgNP apparent extraction efficiency of sample dispersions prepared by the spiking sequence of $\mathrm{Ag}^{+}, \mathrm{AgNPs}$, and $\mathrm{Na}_{2} \mathrm{~S}_{2} \mathrm{O}_{3}$, as well as $\mathrm{Ag}^{+}, \mathrm{Na}_{2} \mathrm{~S}_{2} \mathrm{O}_{3}$, and $\mathrm{AgNPs}$, respectively. It was found that the former sequence showed higher apparent extraction efficiency than the latter one, suggesting that the premixing of $\mathrm{Ag}^{+}$and $\mathrm{Na}_{2} \mathrm{~S}_{2} \mathrm{O}_{3}$ reduced the adsorption of $\mathrm{Ag}^{+}$on AgNPs and thus the apparent extraction of AgNPs.

As TX-114 has a critical micellar concentration (CMC) of 0.01\% $(\mathrm{w} / \mathrm{v}),{ }^{36}$ the TX-114 concentration was optimized in the range of $0.05-0.5 \%(\mathrm{w} / \mathrm{v})$. The extraction efficiency of AgNPs increased with TX-114 concentration up to $0.2 \%(\mathrm{w} / \mathrm{v})$ and then remained constant until 0.4\% (Figure S1 in the Supporting Information). As an increase in the TX-114 concentration caused an increase in the surfactant-rich phase volume and thus reduced the enrichment factor, $0.2 \%(\mathrm{w} / \mathrm{v})$ TX-114 was adopted in the subsequent studies.
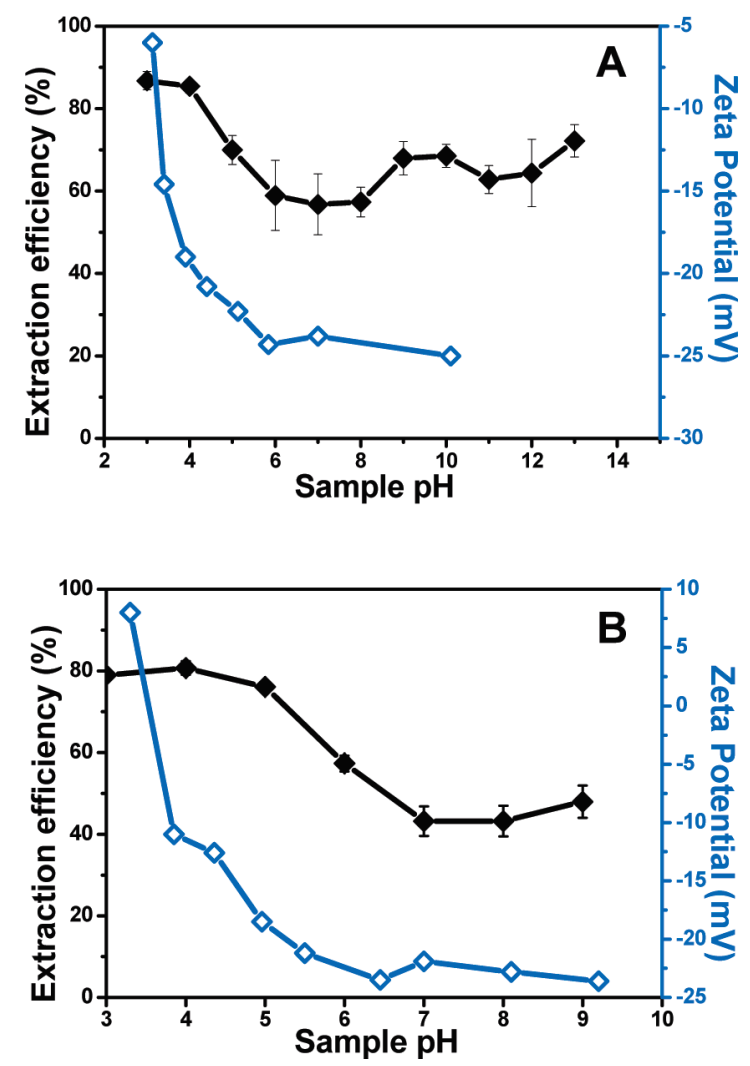

Figure 2. Effect of sample $\mathrm{pH}$ on the $\zeta$ potential (open symbols) and extraction efficiency (solid symbols) of AgNPs: (A) PVP capped AgNPs; (B) commercial AgNPs. To a $10 \mathrm{~mL}$ mixture of $10 \mathrm{mg} / \mathrm{L} \mathrm{Ag}^{+}$ and $0.93 \mathrm{mg} / \mathrm{L}$ AgNPs was added $0.2 \%(\mathrm{~m} / \mathrm{v}) \mathrm{TX}-114$ and $10 \mathrm{mM}$ $\mathrm{Na}_{2} \mathrm{~S}_{2} \mathrm{O}_{3}$. The resulting solution was incubated at $40{ }^{\circ} \mathrm{C}$ for $30 \mathrm{~min}$.

Our previous study ${ }^{35}$ showed that sample $\mathrm{pH}$ played a key role in the CPE of NMs, and the highest extraction efficiency was obtained at the zero point charge $\mathrm{pH}\left(\mathrm{pH}_{\mathrm{PZC}}\right)$ of the target NMs. In this present study, the sample $\mathrm{pH}$ was optimized in the range of $\mathrm{pH} 3.0-13.0$ for the PVP capped AgNPs and $\mathrm{pH} 3.0-9.0$ for the commercial AgNPs. Results showed that the highest extraction efficiency was obtained at about $\mathrm{pH} 3$ (Figure 2), agreeing with the measured $\mathrm{pH}_{\mathrm{PZC}}$ which was $\sim 3.0$ for the $\mathrm{PVP}$ capped AgNPs and 3.5 for the commercial AgNPs. The slight increase of extraction efficiency at above $\mathrm{pH} 8.0$ might be attributed to the coextraction of $\mathrm{Ag}_{2} \mathrm{O}$ formed by the reaction between $\mathrm{Ag}^{+}$and $\mathrm{OH}^{-}$. Considering that the $\mathrm{pH}_{\mathrm{PZC}}$ of some AgNPs were in the range of $1-4$, depending on the coating species, ${ }^{40,41}$ a higher acidity of samples with a $\mathrm{pH}<3.0$ might enhance their extraction efficiency. However, a $\mathrm{pH}<3.0$ is not applicable in this present system due to the possible dissolution of $\mathrm{AgNPs}$, as well as the decomposition of $\mathrm{S}_{2} \mathrm{O}_{3}{ }^{2-}$ and the formation of sulfur precipitation. The ion-selective electrode measurement indicated that the free $\mathrm{Ag}^{+}$concentration in $\mathrm{pH}$ 3.0 dispersions of AgNPs was kept constant in $2 \mathrm{~h}$, suggesting the dissolution of AgNPs was negligible. The constant extraction recovery in the extraction time range of $10-120 \mathrm{~min}$

(40) Alvarez-Puebla, R. A.; Arceo, E.; Goulet, P. J. G.; Garrido, J. J.; Aroca, R. F. J. Phys. Chem. B 2005, 109, 3787-3792.

(41) Dougherty, G. M.; Rose, K. A.; Tok, J. B.-H.; Pannu, S. S.; Chuang, F. Y. S.; Sha, M. Y.; Chakarova, G.; Penn, S. G. Electrophoresis 2008, 29, 11311139. 


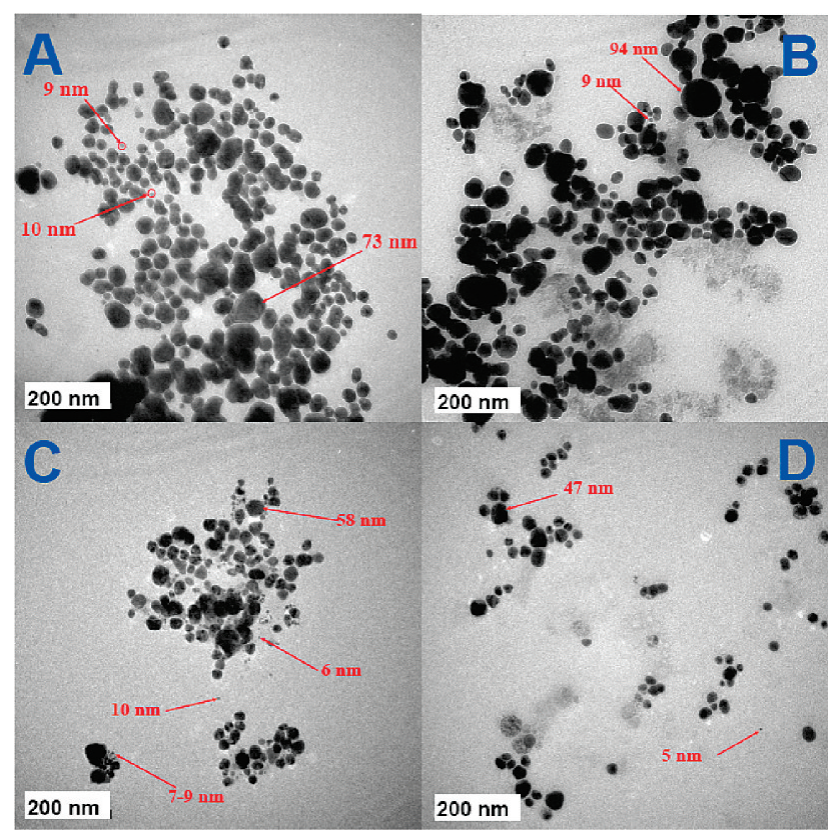

Figure 3. TEM images showing the extraction of AgNPs with wide range of particle size. (A) PVP capped AgNPs in an aqueous solution before extraction. (B) PVP capped AgNPs extracted in the TX-114rich phase. (C) Commercial AgNPs in aqueous solution before extraction. (D) Commercial AgNPs extracted in the TX-114-rich phase.

(Figure S3 in the Supporting Information) also suggested that the dissolution of AgNP during the extraction was negligible.

Other factors taken into account for the optimization are the incubation temperature and time. ${ }^{36-38}$ The extraction efficiency increased with temperature in the range of $25-35^{\circ} \mathrm{C}$, and the highest values were obtained in the range of $35-50{ }^{\circ} \mathrm{C}$. The reduction of extraction efficiency when the temperature was over $50{ }^{\circ} \mathrm{C}$ might be attributed to the reduced association of AgNPs to TX-114 micelles (Figure S2 in the Supporting Information). The effect of incubation time was studied in the range of 5-120 $\mathrm{min}$ at $40{ }^{\circ} \mathrm{C}$. Results revealed that the extraction efficiency increased with time up to $10 \mathrm{~min}$ and then leveled off (Figure S3 in the Supporting Information), indicating that the extraction reached equilibrium in $10 \mathrm{~min}$. In the following studies, extraction was conducted at $40{ }^{\circ} \mathrm{C}$ for $30 \mathrm{~min}$ to ensure complete equilibration.

Effects of AgNP Size. The extraction efficiencies of the two AgNP samples with different particle sizes and capping reagents were tested under the above optimized conditions. Experiments showed that both categories of AgNPs were quantitatively recovered. The extraction efficiencies were $84.8 \pm 1.7 \%$ for the PVP capped AgNPs and $103 \pm 2 \%$ for the commercial AgNPs with unknown capping reagent. The size distribution analysis showed that the average diameter of PVP capped AgNPs in the TX-114rich phase $(35.6 \pm 12.6 \mathrm{~nm})$ agreed with that in the original sample solution $(37.5 \pm 6.0 \mathrm{~nm})$. As shown in Figure 3, the particle diameter range of AgNPs in the TX-114-rich phase (5-47 nm for the commercial AgNPs and 9-94 $\mathrm{nm}$ for the PVP capped AgNPs) agreed with that in the original sample solution $(6-58 \mathrm{~nm}$ for the commercial AgNPs and 9-73 $\mathrm{nm}$ for the PVP capped AgNPs). Overall, Figure 3 indicates that AgNPs with a diameter in the range of $5-94 \mathrm{~nm}$ were successfully extracted by this proposed procedure.



Figure 4. Effects of humic acid (open symbols) and $\mathrm{Ag}^{+}$(solid symbols) on the extraction efficiency of AgNPs. A $10 \mathrm{~mL}$ mixture of $10 \mathrm{mg} / \mathrm{L} \mathrm{Ag}^{+}$and $0.93 \mathrm{mg} / \mathrm{L} \mathrm{AgNPs}$ was used to test the effect of humic acid, while $10 \mathrm{~mL}$ of $0.93 \mathrm{mg} / \mathrm{L}$ AgNPs was adopted for studying the effect of $\mathrm{Ag}^{+}$. To samples were added $0.2 \%(\mathrm{~m} / \mathrm{v}) \mathrm{TX}$ 114 and $10 \mathrm{mM} \mathrm{Na}_{2} \mathrm{~S}_{2} \mathrm{O}_{3}$, and the mixture was adjusted to $\mathrm{pH} 3.0$ and incubated at $40{ }^{\circ} \mathrm{C}$ for $30 \mathrm{~min}$.

Effects of the Interference of $\mathbf{A g}^{+}$. The purpose of this study is to develop a method for concentration of AgNPs in environmental waters; thus, it is important to evaluate the effects of sample matrixes. Since it was reported that dissolved organic matter (DOM) such as humic acid can associate with various NMs to form stable suspensions, ${ }^{42-45}$ it is necessary to study if the presence of humic acid, widely present in environmental water, impacts the extraction efficiency of AgNPs. As shown in Figure 4 , humic acid in an environmentally relevant concentration range $(0-30 \mathrm{mg} / \mathrm{L} \mathrm{DOC})$ has no effect on the extraction of AgNPs. Further, experiments showed that, with the presence of humic acid (12.5 mg/L DOC), the respective extraction efficiency (\%) was $1.58 \pm 0.02$ for $\mathrm{Ag}^{+}, 84.5 \pm 13$ for $\mathrm{AgNPs}$ without $\mathrm{Ag}^{+}$, and $85.0 \pm 2.7$ for $\mathrm{AgNPs}$ with $\mathrm{Ag}^{+}$, suggesting that humic acid had no effect on the extraction of both $\mathrm{Ag}^{+}$and AgNPs. It was expected that humic acid should form a complex with $\mathrm{Ag}^{+}$and thus enhance the extraction of $\mathrm{Ag}^{+}$into the TX-114-rich phase. The negligible extraction of $\mathrm{Ag}^{+}$in the presence of humic acid might be attributed the strong association of $\mathrm{S}_{2} \mathrm{O}_{3}{ }^{2-}$ with $\mathrm{Ag}^{+}$, which prevents the formation of a complex between $\mathrm{Ag}^{+}$and humic acid.

As discussed above, the coexisting $\mathrm{Ag}^{+}$cations might be adsorbed on the surface of AgNPs and be extracted together with AgNPs. This could result in positive errors, as the $\mathrm{Ag}^{+}$ would be falsely counted as AgNPs in the following ICPMS determination. To test the interference of $\mathrm{Ag}^{+}$, dispersions with constant AgNPs $(0.93 \mathrm{mg} / \mathrm{L})$ and varied $\mathrm{Ag}^{+}(0-10 \mathrm{mg} / \mathrm{L})$ were premixed to ensure the sorption equilibration of $\mathrm{Ag}^{+}$to AgNPs and then extracted at the optimized conditions. Results shown in Figure 4 indicate that the interference of $\mathrm{Ag}^{+}$was negligible when the concentration of $\mathrm{Ag}^{+}$was not over 2 times that of AgNPs.

(42) Hyung, H.; Fortner, J. D.; Hughes, J. B.; Kim, J. H. Environ. Sci. Technol. 2007, 41, 179-184.

(43) Giasuddin, A. B. M.; Kanel, S. R; Choi, H. Environ. Sci. Technol. 2007, 41, 2022-2027.

(44) Diegoli, S.; Manciulea, A. L.; Begum, S.; Jones, I. P.; Lead, J. R.; Preece, J. A. Sci. Total Environ. 2008, 402, 51-61.

(45) Ghosh, S.; Mashayekhi, H.; Pan, B.; Bhowmik, P.; Xing, B. Langmuir 2008, 24, 12385-12391. 
Adsorption of AgNPs on the Vessels. Unlike the common inorganic analytes such as metal ions, NMs were reported to adsorb significantly to the test vessels. ${ }^{8,10,28}$ To test the adsorption of AgNPs on the surface of the vessels used in this proposed procedure, three samples, $\mathrm{Ag}^{+}$, AgNPs, and a mixture of $\mathrm{Ag}^{+}$and AgNPs, were extracted with the proposed procedure. After phase separation, the $\mathrm{Ag}$ contents in the TX-114-rich phase and the water-rich phase were determined, respectively. Mass balance was evaluated with the recovery, which was calculated on the basis of the sum of $\mathrm{Ag}$ contents in the two phases relative to the spiked amount of Ag. Results (Table S1 in the Supporting Information) indicate that the recoveries were around 95\%, demonstrating the adsorption of $\mathrm{Ag}^{+}$and AgNPs on the container was less than $5 \%$ and thus negligible.

ICPMS Quantification. In this present study, AgNPs were quantified by ICPMS determination of the Ag concentration in the digestion solution of the TX-114-rich phase, which was obtained with the above optimized CPE procedure. The analytical performance of the proposed procedure was evaluated by determining parameters, such as linearity of the calibration curve, reproducibility, and enrichment factor, with AgNP dispersions. By testing 17 dispersions containing $0,0.025,0.05,0.1,0.25,0.5$, 1.0, 2.5, 5.0, 10, 20, 50, 100, 500, 1000, 2500, and $5000 \mu \mathrm{g} / \mathrm{L} \mathrm{AgNPs,}$ the obtained linearity was very satisfactory with correlation coefficients $\left(r^{2}\right)$ of 0.9992 in the entire range of $0-5000 \mu \mathrm{g} / \mathrm{L}$ AgNPs, 0.9964 in the range of $0-100 \mu \mathrm{g} / \mathrm{L}$ AgNPs, and 0.9984 in the range of $0-5 \mu \mathrm{g} / \mathrm{L}$ AgNPs, respectively. The reproducibility was determined by extracting six water samples spiked with $100 \mu \mathrm{g} / \mathrm{L}$ AgNPs. The obtained recovery was $88.8 \%$ with a relative standard deviation (RSD) of $5.6 \%$. The enrichment factor, calculated on the basis of a TX-114-rich phase volume of $100 \mu \mathrm{L}$, was 100 . The detection limit, defined as 3 times the baseline noise $(\mathrm{S} / \mathrm{N}=3)$, was $0.006 \mu \mathrm{g} / \mathrm{L}$ which corresponded to $34.3 \mathrm{fmol} / \mathrm{L}$ particles of AgNPs (calculated on the basis of the average diameter of $37.5 \mathrm{~nm}$ and assuming AgNPs has the same density as Ag metal). This detection limit is considered very low and should satisfy the requirement for detection of AgNPs in environmental samples, as a previous published model predicted concentrations of AgNPs arising from the use of consumer products to be $0.01 \mu \mathrm{g} / \mathrm{L}$ in water and $0.43 \mu \mathrm{g} /$ $\mathrm{kg}$ in soil, respectively. ${ }^{10}$

Identification of AgNPs. Since $\sim 1.6 \%$ of $\mathrm{Ag}^{+}$in water samples was extracted into the TX-114-rich phase by this proposed CPE procedure (Table S1 in the Supporting Information), the Ag in the TX-114-rich phase detected by ICPMS could be either $\mathrm{AgNPs}$ or $\mathrm{Ag}^{+}$. Thus, experiments were performed to verify the presence of AgNPs, and results were shown in Figure 5. The presence of nanoparticles in the TEM images of TX-114rich phases, separated from the extraction of 10 and $25 \mu \mathrm{g} / \mathrm{L}$ sample dispersions, suggests the presence of AgNPs. SEM-EDS analysis excluded the existence of silver halide NMs, as no halide was detected in the EDS analysis. The high contents of sulfur and carbon shown in the EDS analysis (Figure 5E) were attributed to the $\mathrm{S}_{2} \mathrm{O}_{3}{ }^{2-}$ used in the extraction system and the carbon supporter used for sample preparation.

To further verify the presence of AgNPs, the separated TX114-rich phase was collected to record the UV-vis absorbance
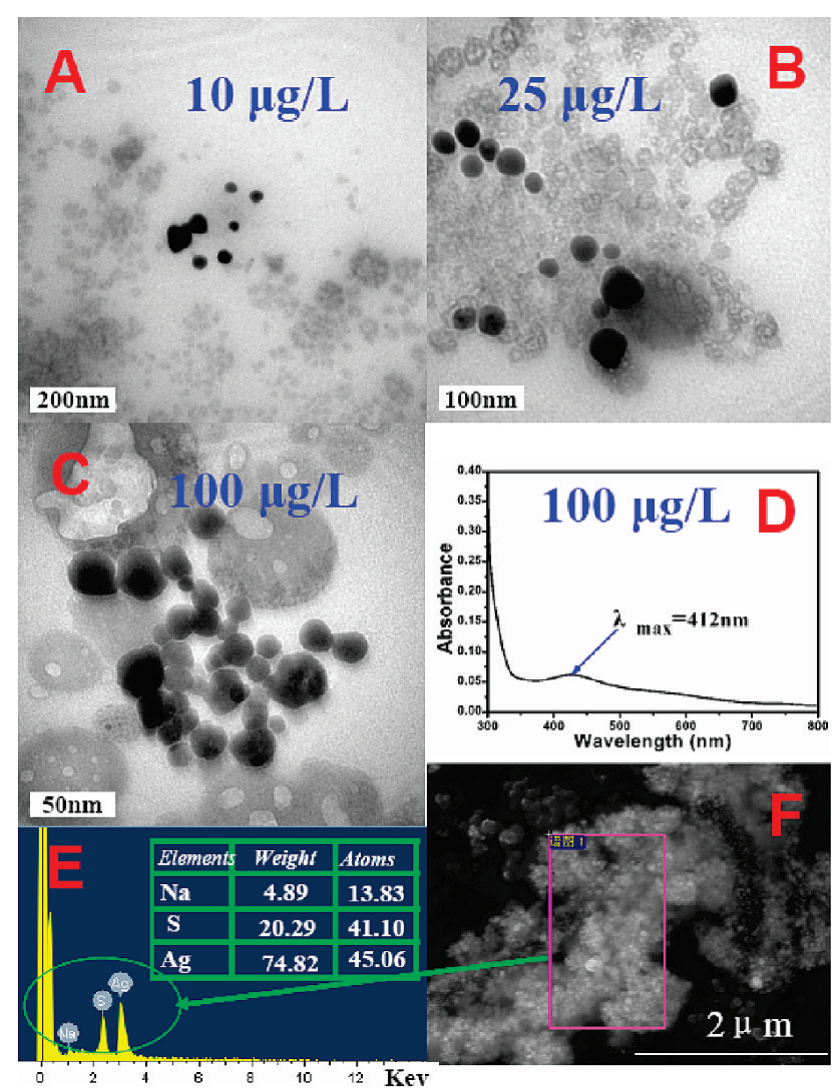

Figure 5. Identification of AgNPs enriched in the TX-114-rich phase. TEM images of the TX-114-rich phase separated from the extraction of samples containing $10 \mu \mathrm{g} / \mathrm{L}(\mathrm{A})$ and $25 \mu \mathrm{g} / \mathrm{L}$ (B) AgNPs. TEM image (C) and UV-vis spectrum (D) of the TX-114-rich phase separated from extraction of a sample containing $100 \mu \mathrm{g} / \mathrm{L}$ AgNPs. EDS (E) and SEM image (F) of the TX-114-rich phase separated from the extraction a sample containing $1 \mathrm{mg} / \mathrm{L}$ AgNPs.

spectrum. As shown in Figure 5D, the TX-114-rich phase from AgNP dispersions exhibited a maximum absorbance of $412 \mathrm{~nm}$, which agreed with the characteristic maximum absorbance of AgNPs $(\sim 410 \mathrm{~nm})^{46}$ and thus demonstrated the presence of AgNPs. It is noteworthy that Figure 5D was obtained with $\mathrm{NaNO}_{3}$ as the salt for facilitating phase separation. When $\mathrm{Na}_{2} \mathrm{~S}_{2} \mathrm{O}_{3}$ was added into the extraction system for phase separation, however, the characteristic absorbance was concealed by the absorbance of TX-114 and $\mathrm{Ag}_{2} \mathrm{~S}_{2} \mathrm{O}_{3}$. Therefore, $\mathrm{NaNO}_{3}$ rather than $\mathrm{Na}_{2} \mathrm{~S}_{2} \mathrm{O}_{3}$ was recommended for facilitating phase separation when UV-vis was used to identify AgNPs.

Real Sample Analysis. To further evaluate the applicability of the proposed method, real environmental water samples were analyzed and the recoveries were determined by spiking $0.1-146$ $\mu \mathrm{g} / \mathrm{L}$ AgNPs. To study the recovery of different AgNPs in real water samples, both the PVP stabilized AgNPs and the commercial AgNPs were tested. As shown in Table 2, the Ag contents in the tested environmental waters were in the range of $1.27-2.89 \mu \mathrm{g} /$ $\mathrm{L}$, which should be $\mathrm{Ag}^{+}$or AgNPs with sizes below $5 \mathrm{~nm}$, as TEM and EDS test did not identify any AgNPs in the TX-114rich phase. The obtained recoveries of AgNPs were in the range of $57-116 \%$, which was satisfactory with regard to the low spiking level $(0.1-146 \mu \mathrm{g} / \mathrm{L})$. No significant difference between recoveries for samples with or without filtration was

(46) Mie, G. Ann. Phys. 1908, 25, 377-445. 


\begin{tabular}{|c|c|c|c|c|c|}
\hline \multirow[b]{2}{*}{ sample } & \multirow[b]{2}{*}{ spiked AgNPs $(\mu \mathrm{g} / \mathrm{L})$} & \multirow[b]{2}{*}{ detected $\mathrm{Ag}(\mu \mathrm{g} / \mathrm{L}$, mean $\pm s, n=3)$} & \multirow[b]{2}{*}{ recovery $(\%)$} & \multicolumn{2}{|c|}{ identification of NPs } \\
\hline & & & & TEM & UV-vis \\
\hline \multirow[t]{2}{*}{ effluents of WWTP without filtration } & 0 & $2.89 \pm 0.83$ & & - & - \\
\hline & 25 & $19.3 \pm 0.8$ & $77 \pm 3$ & + & - \\
\hline \multirow{4}{*}{ effluents of WWTP with filtration } & 0 & $2.16 \pm 0.34$ & & - & - \\
\hline & 0.1 & $0.066 \pm 0.007$ & $66 \pm 7$ & - & - \\
\hline & 25 & $18.4 \pm 0.9$ & $74 \pm 3$ & + & - \\
\hline & $146^{b}$ & $148 \pm 4$ & $101 \pm 4$ & + & + \\
\hline \multirow[t]{2}{*}{ influents of WWTP without filtration } & 0 & $2.49 \pm 0.59$ & & - & - \\
\hline & 25 & $15.2 \pm 2.4$ & $61 \pm 10$ & + & - \\
\hline \multirow{4}{*}{ influents of WWTP with filtration } & 0 & $1.89 \pm 0.16$ & & - & - \\
\hline & 0.1 & $0.057 \pm 0.006$ & $57 \pm 6$ & - & - \\
\hline & 25 & $17.1 \pm 1.4$ & $68 \pm 6$ & + & - \\
\hline & $146^{b}$ & $164 \pm 5$ & $112 \pm 4$ & + & + \\
\hline \multirow[t]{2}{*}{ lake water without filtration } & 0 & $1.49 \pm 0.18$ & & - & - \\
\hline & 20 & $15.2 \pm 0.6$ & $76 \pm 3$ & + & - \\
\hline \multirow{4}{*}{ lake water with filtration } & 0 & $1.78 \pm 0.15$ & & - & - \\
\hline & 0.1 & $0.064 \pm 0.009$ & $64 \pm 12$ & - & - \\
\hline & 25 & $25.7 \pm 1.3$ & $103 \pm 5$ & + & - \\
\hline & $146^{b}$ & $135 \pm 9$ & $92 \pm 6$ & + & + \\
\hline \multirow{2}{*}{ river water without filtration } & 0 & $1.27 \pm 0.08$ & & - & - \\
\hline & 25 & $18.5 \pm 1.3$ & $74 \pm 5$ & + & - \\
\hline \multirow[t]{4}{*}{ river water with filtration } & 0 & $1.44 \pm 0.22$ & & - & - \\
\hline & 0.1 & $0.064 \pm 0.005$ & $64 \pm 5$ & - & - \\
\hline & 25 & $20.1 \pm 0.6$ & $80 \pm 2$ & + & - \\
\hline & $146^{b}$ & $169 \pm 4$ & $116 \pm 3$ & + & + \\
\hline
\end{tabular}

${ }^{a}$ PVP capped AgNPs was spiked, otherwise specified. ${ }^{b}$ Spiked with commercial AgNPs (Silcryst nanocrystalline silver).

observed (Table 2), suggesting that the presence of natural particles in the samples had no significant effects on the CPE of AgNPs at concentrations $\geq 20 \mu \mathrm{g} / \mathrm{L}$. For all the samples spiked with $\mathrm{AgNPs}$ at concentrations $\geq 20 \mu \mathrm{g} / \mathrm{L}$, nanoparticles were observed in the TEM images of the TX-114-rich phase. When the water samples were spiked with $146 \mu \mathrm{g} / \mathrm{L} \mathrm{AgNPs}$ and $\mathrm{NaNO}_{3}$ was adopted for phase separation, the UV-vis spectra of the TX114-rich phase exhibited an absorbance peak with $\lambda_{\max }=412$ $\mathrm{nm}$. This result indicates that UV-vis spectroscopy can be adopted to identify and quantify the AgNP content in environmental samples.

\section{CONCLUSIONS}

For the first time, TX-114-based CPE was demonstrated to be an efficient approach for selective extraction and concentration of trace $\mathrm{AgNPs}$ from environmental water samples without disturbing their sizes and shapes. $\mathrm{Na}_{2} \mathrm{~S}_{2} \mathrm{O}_{3}$ was added into the extraction system to function as a complex reagent of $\mathrm{Ag}^{+}$to prevent its extraction into the TX-114-rich phase and as a salt to enhance the extraction of AgNPs. The AgNPs preconcentrated in the TX-114-rich phase can be directly identified by
TEM/SEM-EDS/UV-vis and quantified after microwave digestion by ICPMS with a very low detection limit. Furthermore, as the extraction procedure preserves the sizes and shapes of AgNPs, the original morphology of AgNPs in environmental waters can be obtained by characterizing the AgNPs preconcentrated in the TX-114-rich phase. This proposed method provided a novel approach for characterization and quantification of AgNPs in environmental water samples, which can further contribute to understanding the fate and toxicity of AgNPs in aqueous systems.

\section{ACKNOWLEDGMENT}

This work was jointly supported by the National Natural Science Foundation of China (20877082, 20621703).

\section{SUPPORTING INFORMATION AVAILABLE}

Additional information as noted in text. This material is available free of charge via the Internet at http://pubs.acs.org.

Received for review April 29, 2009. Accepted June 22, 2009.

\section{AC900918E}

